\title{
n-6 fatty acid metabolism in the newborn infant: is linoleic acid sufficient to meet the demand for arachidonic acid?
}

\author{
Robert J. PAWLOSKY \\ Laboratory of Metabolic Control, \\ National Institutes on Alcohol Abuse \\ \& Alcoholism, NIH, \\ Rm 1S-22 5625 Fishers Lane, \\ Bethesda, MD 20892, \\ Bethesda, Maryland, USA \\ <bpawl@mail.nih.gov>
}

\begin{abstract}
Two compartmental models were developed to assess the contributions of linoleic acid, 18:2n-6, and di-homo-g-linoelic acid, 20:3n-6, toward maintaining plasma homeostasis concentrations of arachidonic acid, 20:4n-6, in newborn infants. Ten infants received oral doses of ${ }^{13} \mathrm{C}-U-18: 2 n-6$ and ${ }^{2} \mathrm{H}_{5}-20: 3 n-6$ ethyl esters (100 and $2 \mathrm{mg} \mathrm{kg}^{-1}$, respectively). Rate constant coefficients of $n-6$ FAs were determined from the time-course concentrations of labeled-FAs and endogenous plasma n-6 FA values were used to approximate steady state concentrations. Eight percent (range: 2-21\%) of plasma ${ }^{13} \mathrm{C}-\mathrm{U}-18: 2 n-6$ was utilized for synthesis of ${ }^{13} \mathrm{C}-18: 3 n-6,-20: 2 n-6$ and $-20: 3 n-6$ and $70 \%$ of ${ }^{13} \mathrm{C}-20: 3 \mathrm{n}-6$ (mean, CV: 0.26) was available for synthesis of ${ }^{13} \mathrm{C}-20: 4 n-6$. The percentage of ${ }^{2} \mathrm{H}_{5}$ 20:3n-6 converted to ${ }^{2} \mathrm{H}_{5}-20: 4 n-6$ was only $26 \%$. Turnover of 18:2n-6 in subjects and of 20:4n-6 in plasma was $4.2 \mathrm{~g} \mathrm{~kg}^{-1} \mathrm{~d}^{-1}(\mathrm{CV}: 0.58)$ and $4.3 \mathrm{mg} \mathrm{kg}^{-1} \mathrm{~d}^{-1}$ (CV: 0.81$)$, respectively. Intake of $18: 2 \mathrm{n}-6$ and 20:4n-6 were estimated to be $3.0 \mathrm{~g} \mathrm{~kg}^{-1} \mathrm{~d}^{-1}( \pm 1.7)$ and $2.8 \mathrm{mg} \mathrm{kg}^{-1} \mathrm{~d}^{-1}( \pm 2.2)$, respectively. Infants required additional $18: 2 \mathrm{n}-6\left(1.2 \mathrm{~g} \mathrm{~kg}^{-1} \mathrm{~d}^{-1}\right)$ above predicted intake amounts to maintain plasma concentrations of 18:2n-6. The percent conversion of 18:2n-6 to 20:4n-6 was incapable of sustaining plasma 20:4n-6 concentrations in nearly all subjects necessitating a supplemental intake of $\sim 4 \mathrm{mg} \mathrm{kg}^{-1}$ $d^{-1}$ of $20: 4 n-6$.
\end{abstract}

Key words: infants, fatty acid metabolism, linoleic acid, compartmental model, kinetics, arachidonic acid, isotope tracer

Analysis Modeling) program. The n-6 FA kinetic parameters were determined for each subject and mean values were calculated for the cohort. Quantitative contributions of dietary 18:2n-6 and 20:3n-6 toward maintenance of plasma $20: 4 n-6$ during the first week of life were determined.

\section{Methods}

acids are required in the diet daily to meet the metabolic demands of newborns [1, 2]. To this end, two compartmental models were developed using isotope tracer data to assess the contributions of both $18: 2 n-6$ and 20:3n-6 toward maintaining plasma concentrations of 20:4n-6 in gestational age-appropriate newborn infants during the first week of life.

During the early postnatal period placental transfer of nutrients ceases and infants rapidly develop an increasing capacity to nurse. Body weight decreases (typically, infants loose $5-10 \%$ body weight during the first week of life) and body fat reserves are recruited to meet the demand for energy. Consequently, the balance of energy equilibrium shifts during the early postnatal period which is likely to have an impact on lipid metabolism until intake volumes become established.

Two independent compartmental models were developed from the plasma masses of endogenous n-6 FAs and isotopic tracer data of the ${ }^{13} \mathrm{C}$-labeled $\mathrm{n}-6$ (from ${ }^{13} \mathrm{C}-18: 2 \mathrm{n}-6$ ) and the ${ }^{2} \mathrm{H}_{5}$-labeled $\mathrm{n}-6$ (from ${ }^{2} \mathrm{H}_{5}-20: 3 \mathrm{n}-6$ ) FAs using the WinSAAM (Windows Simulation, and

\section{Subject characteristics and clinical procedures}

A description of the subject characteristics and clinical procedures may be found elsewhere [3] but are briefly outlined here. Table 1 gives a brief description of subject data and feeding regimen. Infants $(n=10)$, with gestational ages greater than $34 \mathrm{wk}$ were accepted into the protocol after receiving informed consent from the mothers and admitted to the Hospital Sótero del Rio and Clínica Presbiteriana MadreHijo in Santiago, Chile. Feeding was started generally within $2 \mathrm{~d}$ after birth, and the type of feeding varied. If breast milk was unavailable, infants received Similac ${ }^{\circledR}$ infant formula (Ross Labs, Abbott Park, IL) which contained 18:2n-6 (780 mg $100 \mathrm{~mL}^{-1}$ ) but devoid of 20:3n-6 and 20:4n-6. Infants were nursed and/or fed expressed breast milk when available, and/or Similac ${ }^{\circledR}$ infant formula upon demand. The quantity of expressed milk and the amount of formula consumed were determined for each subject. Subjects received a mixture of ${ }^{13} \mathrm{C}-\mathrm{U}$ 18:2n-6 (100 mg kg-1) and deuterated ${ }^{2} \mathrm{H}_{5}$ 20:3n-6 (2 mg kg-1). Blood was drawn $(0.5 \mathrm{~mL})$ from an umbilical catheter or from a peripheral vein, into a tube containing EDTA. Blood was drawn at $0,4,8,24$ and $48 \mathrm{~h}$ and on the $4^{\text {th }}$ and $7^{\text {th }} \mathrm{d}$ after dosing. Plasma was separated by centrifugation and frozen at $-80^{\circ} \mathrm{C}$.

\section{Stable isotopes}

Carbon-13-uniformly-labeled linoleate $\left({ }^{13} \mathrm{C}-\mathrm{U}\right.$ $\left.18: 2 \mathrm{n}-6,{ }^{13} \mathrm{C}>95 \%\right)$ and deuterium labeled di-homo- $\gamma$-linolenate $\left(19,19,20,20,20-{ }^{2} \mathrm{H}_{5}\right.$ $20: 3 n-6,{ }^{2} \mathrm{H}>95 \%$ ) ethyl esters were greater than $95 \%$ chemical purity (Cambridge Isotope Laboratories, Andover, MA).

\section{Lipid extraction and analytical procedures}

A complete description of the lipid extraction procedures and gas chromatography (GC) and GC-mass spectrometry (MS) conditions may be found elsewhere [4]. Plasma lipids were extracted using a modified Folch procedure [5]. Plasma lipids were analyzed as their methyl esters by GC analysis on a polar capillary column with flame ionization detection. Fatty acids were also derivatized to their Pentafluorobenzyl esters and analyzed using negative chemical ionization GC-MS analysis. 
Table 1. Subject description and feedind intake data.

\begin{tabular}{|c|c|c|c|c|c|c|c|c|c|}
\hline ID & $\begin{array}{l}\text { BW } \\
\text { (g) }\end{array}$ & $\begin{array}{c}\text { GA } \\
\text { (wks) }\end{array}$ & Sex & $\begin{array}{c}\text { Age at } \\
\text { entrance } \\
\text { (d) }\end{array}$ & $\begin{array}{c}\text { Wt } \\
\text { at entrance } \\
\text { (g) }\end{array}$ & $\begin{array}{c}\text { W } \\
\text { at end } \\
(g)\end{array}$ & $\begin{array}{c}\text { Age at enteral } \\
\text { feeding } \\
\text { (d) }\end{array}$ & $\begin{array}{c}\text { Formula } \\
\text { intake } \\
\mathrm{mL} / \text { day }\end{array}$ & $\begin{array}{c}\text { Breast milk } \\
\text { intake } \\
\text { mL/day }\end{array}$ \\
\hline 82 & 3250 & 38 & $\mathrm{~F}$ & 1 & 3400 & 3550 & 4 & 136 & 143 \\
\hline 83 & 3890 & 42 & $M$ & 1 & 3930 & 3920 & 2 & 38 & 390 \\
\hline 84 & 3070 & 39 & $M$ & 3 & 3080 & 3250 & 3 & 110 & 405 \\
\hline 86 & 2350 & 36 & $M$ & 2 & 2390 & 2170 & 4 & 0 & 70 \\
\hline 87 & 3070 & 37 & $M$ & 3 & 3060 & 2940 & 3 & 165 & 136 \\
\hline 88 & 3310 & 39 & $M$ & 4 & 3510 & 3510 & 4 & 180 & 0 \\
\hline 89 & 3160 & 37 & $M$ & 2 & 3410 & 3480 & 3 & 234 & 10 \\
\hline 90 & 2540 & 35 & $M$ & 1 & 2550 & 2270 & 2 & 0 & 60 \\
\hline 91 & 4650 & 41 & $\mathrm{~F}$ & 2 & 4580 & 4680 & 3 & 169 & 44 \\
\hline 92 & 2490 & 37 & $\mathrm{M}$ & 2 & 2440 & 2350 & 3 & 0 & 130 \\
\hline
\end{tabular}

Abbreviations. ID (patient ID): BW (body weight): GA (gestional age).

\section{Compartmental models}

The compartmental models were developed based on the existing knowledge of fat absorption, n-6 FA metabolism, and circulation of lipids in blood. Two independent compartmental models of $n-6$ FA metabolism (figures 1 and 2) were developed using the concentration time-courses of the labeled-FAs and concentrations of endogenous FA in plasma using WinSAAM (http://www.winsaam.com). The fractional transfer rate constant coefficient, $\mathrm{L}_{1, \mathrm{\prime}}$ is the fraction of substrate transferred from substrate-compartment, J, to productcompartment, I. The units are in $\mathrm{h}^{-1}$. $\mathrm{L}_{1, \mathrm{~J}}$ represents an assemblage of several independent enzymatic and transport processes, each having a separate rate constant, for which no intermediates were isolated. The rate of flow $\left(\mathrm{R}_{\mathrm{l}, \mathrm{f}}\right)$ (table 2) from substrate-compartment I to product-compartment I is obtained by multiplying the mass $\left(\mathrm{M}_{\mathrm{t}}\right)$ (table 3 ) of endogenous FA in compartment J by $L_{1, l}$ and is given in $\mu \mathrm{g}$ $\mathrm{h}^{-1}$. The percentage of isotope transferred from $J$ to $I$ is given as $P_{1, J}$ (table 4 ) and is a percent of the total flux of FA leaving J. $P_{1, J}$ is the fraction of isotope remaining in the metabolic pathway as opposed to isotope taken up by tissues or in other ways irreversibly lost from the compartment.

The compartmental model for 18:2n-6 consisted of six compartments (figure 1). Compartment 1 represents the dose of the labeled-FA absorbed through the gastrointestinal tract. Compartments 2, 3, 4, 5 and 7 denote plasma pools of $18: 2 n-6,20: 3 n-6,20: 4 n-6,18: 3 n-6$, and $20: 2 n-6$. Arrows connecting the six compartments indicate flow along the path. The rate equations are defined by a set of differential equations corresponding to flux of labeled-FA through each respective compartment and those that exit the system.

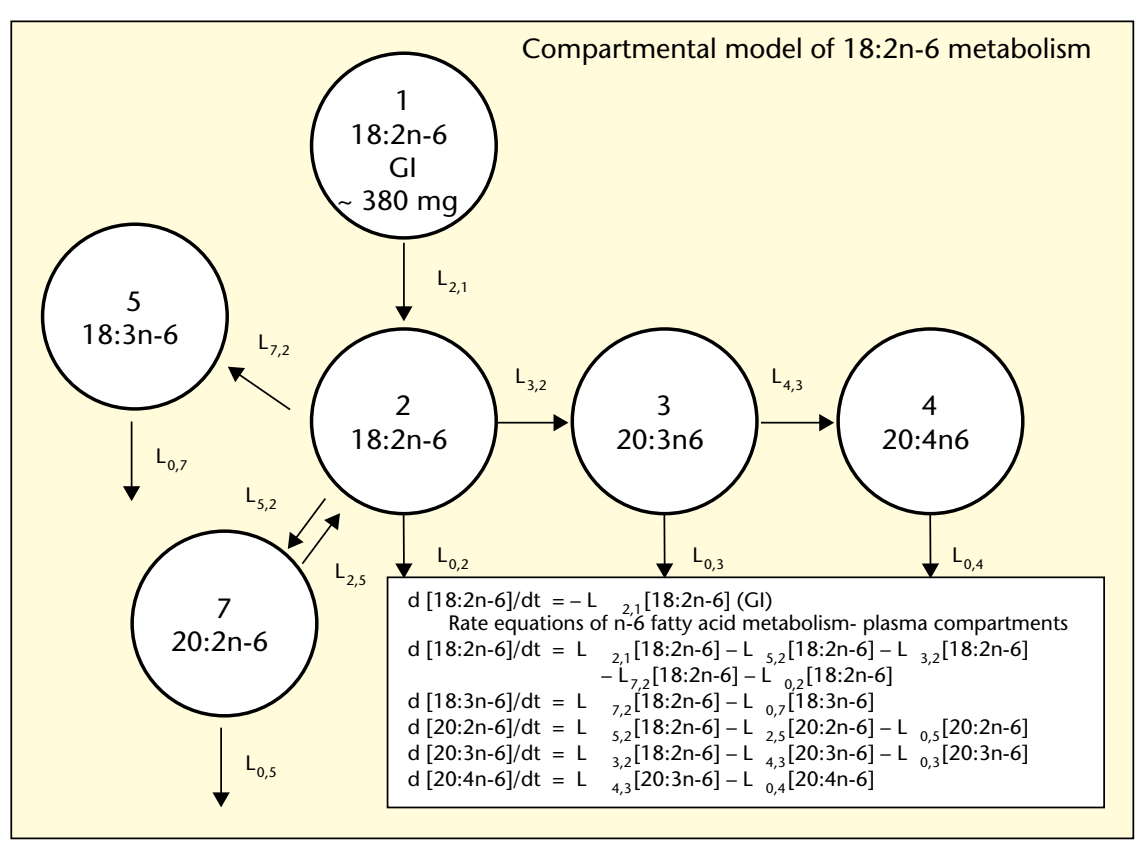

Figure 1. Diagram of compartmental model for 18:2n-6 metabolism. Open circles represent plasma and gastrointestinal (GI) compartments for the $n-6$ fatty acids. $L(j)$ values represent kinetic constants that were determined from the model calculations. $L_{0, j}$ values indicate loss of isotope from the pathway. In the boxed area are the differential equations which pertain to appearance and disappearance of isotope in the various compartments.

\section{Constraints and limits}

Plasma n-6 FA concentrations, determined from mean values over $168 \mathrm{~h}$ for each subject, were used to represent the mass of endogenous substrates $\left(M_{\mathrm{f}}\right)$ available for biosynthesis (table 3) and these values were held constant. For purposes of estimating a daily n-6 FA intake for each subject, the FA content of the infant formula, availability of breast milk, and frequency of feeding were entered into the model (table 1). To determine differences between the efficacy of the two precursors (18:2n- 6 and $20: 3 n-6)$ toward synthesis of 20:4n-6, a paired t-test analysis was performed on values of the rate parameters using each subject as its own control. A p-value of .05 or lower was considered significant.

\section{Calculations, errors, and predicting dietary n-6 FA intake}

Initial $L_{1, j}$ and $P_{1, j}$ estimates, derived from the concentration-time curves, were adjusted to compensate for individual variances in plasma data until the model prediction gave the best fit to the experimental data. Final values were determined using an iterative non-linear least squares routine. The error model included 


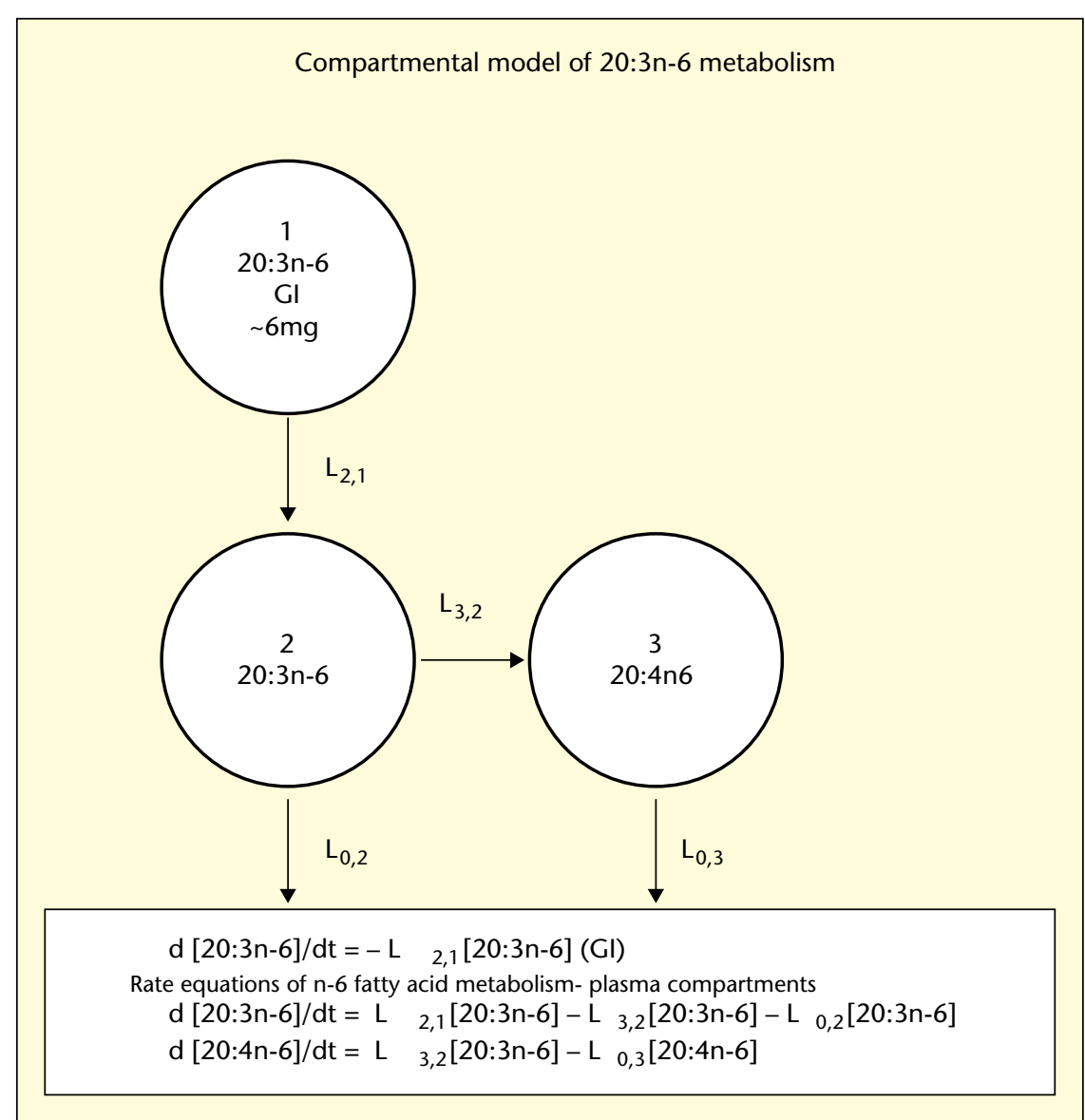

Figure 2. Diagram of compartmental model for 20:3n-6 metabolism. Open circles represent plasma and gastrointestinal (GI) compartments for the $n-6$ fatty acids. $L(j)$ values represent kinetic constants that were determined from the model calculations. In the boxed area are the differential equations which pertain to appearance and disappearance of isotope in the various compartments.

assumptions of independence, constant variance, and normal distribution about zero. Consistent with the precision of analytical methods, data points were weighted by assigning a fractional standard deviation of 0.1 to each measurement. Daily dietary n-6 FA intake val-

\section{Results and discussion}

Ten ( 8 male and 2 female) infants completed the protocol. Most received supplemental feeding with breast milk and/or infant formula in increasing volume during the study. Two 18:2n-6 compartments, one for the isotope administration $(\mathrm{Gl})$ and the second for the appearance of the FA in the plasma were incorporated into the model (figure 1). Approximately $94 \%$ of labeled-18:2n-6 ethyl ester was absorbed (range: $89-99 \%$ ) based on the amount of isotope recovered from the feces over $48 \mathrm{~h}$. Using the area under the curve calculation (AUC), the mean value of ${ }^{13} \mathrm{C}-\mathrm{U}$ $18: 2 n-6( \pm S D)$ appearing in the plasma was $254.5 \pm 58.5 \mathrm{nmol} \cdot \mathrm{mL}^{-1} \mathrm{~h}$. The mean AUC value for ${ }^{2} \mathrm{H}_{5}-20: 3 \mathrm{n}-6$ (AUC $\pm S D$ ) appearing in the plasma was $8.5 \pm 3.9 \mathrm{nmol} \cdot \mathrm{mL}^{-1} \mathrm{~h}$.

The synthetic and utilization rates, $\mathrm{R}_{\mathrm{x}, \mathrm{J}}$ (table 2) represent the total mass of each $n-6$ FA that exit the substrate compartment J and is either transferred to product compartment I or leaves the pathway (0) (but not necessarily the system). The mean value for turnover of $18: 2 \mathrm{n}-6$ through the system was $4.2 \mathrm{~g} \mathrm{~kg}^{-1} \mathrm{~d}^{-1}$ (CV: 0.58$)$ and the mean turnover of $18: 2 n-6$ in the plasma $\left(R_{0,2}\right)$ was $43 \mathrm{mg} \mathrm{d}^{-1}$ (CV 0.65) for the group. The high turnover rate may be associated with the very early postnatal period and as the intake of breast milk and/or formula increases this value may moderate reflecting the change in the lipid composition of the diet [6]. However, consistent with the present findings a high fractional turnover of 18:2n-6 (mean value $93.7 \% \mathrm{~d}^{-1}$ ) was also observed in adult male subjects [7]. The mean daily turnover in $\mathrm{mg} \mathrm{d}^{-1}$ of the other $\mathrm{n}-6 \mathrm{FA}$ in the plasma were: 0.41 (CV 0.50), 2.4 (CV 0.49), 0.73 (CV 0.81) and 10.2 (CV 0.74) for 18:3n-6, 20:2n-6, 20:3n-6 and 20:4n-6, respectively. The mean rate of synthesis of $20: 4 n-6$ from 20:3n-6 $\left(R_{4,3}\right)$ was $39.2 \mu \mathrm{g} \mathrm{h}^{-1}$ or $0.94 \mathrm{mg} \mathrm{d}^{-1}$

Table 2. Synthetic and disappearance rates for $n-6$ fatty acids in plasma.

\begin{tabular}{|c|c|c|c|c|c|c|c|c|c|c|c|c|c|}
\hline \multicolumn{6}{|c|}{ Disappearances and synthetic rates } & \multicolumn{8}{|l|}{$\mu \mathrm{g} \mathrm{hr} r^{-1}$} \\
\hline & 82 & 83 & 84 & 86 & 87 & 88 & 89 & 90 & 91 & 92 & Mean & SD & cv \\
\hline $\mathrm{R}_{0,1}$ & 399340 & 1010500 & 194200 & 268610 & 71826 & 149890 & 274010 & 117800 & 1432300 & 27594 & 394607 & 229863 & 0.58 \\
\hline $\mathrm{R}_{3,2}$ & 8.8 & 5.2 & 3.8 & 4.0 & 16.4 & 2.1 & 49.2 & 2.9 & 16.0 & 10.4 & 11.9 & 7.0 & 0.59 \\
\hline$R_{5,2}$ & 5.0 & 4.1 & 5.7 & 13.8 & 39.4 & 3.3 & 16.0 & 1.7 & 9.0 & 7.1 & 10.5 & 5.6 & 0.53 \\
\hline $\mathrm{R}_{0,2}$ & 585 & 1427 & 753 & 396 & 219 & 331 & 6027 & 1629 & 6215 & 332 & 1791 & 1165 & 0.65 \\
\hline $\mathrm{R}_{7,2}$ & 11.4 & 4.8 & 7.8 & 56.6 & 21.2 & 4.6 & 55.3 & 3.0 & 41.7 & 9.3 & 21.6 & 10.7 & 0.50 \\
\hline $\mathrm{R}_{0,7}$ & 5.8 & 6.3 & 25.9 & 29 & 10.1 & 10.9 & 51.7 & 8.2 & 25.3 & 10.0 & 17.1 & 7.5 & 0.44 \\
\hline $\mathrm{R}_{0,5}$ & 18.6 & 6.2 & 34.5 & nd & 131 & 150 & 58.1 & 257 & 14.9 & 96.1 & 100 & 45 & 0.45 \\
\hline $\mathrm{R}_{4,3}$ & 25.3 & 20.0 & 23.0 & 2.3 & 33.7 & 11.1 & 87.5 & 56.9 & 76.2 & 56.0 & 39.2 & 14.2 & 0.36 \\
\hline $\mathrm{R}_{0,3}$ & 0.5 & 6.3 & 59.7 & 143 & 19.0 & 15.4 & 8.7 & 1.0 & 2.5 & 49.0 & & 22 & 0.73 \\
\hline $\mathrm{R}_{0,4}$ & 99.3 & 212 & 210 & 2120 & 507 & 68.4 & 662 & 0 & 146 & 211 & & 315 & 0.74 \\
\hline
\end{tabular}

Ri,j values are disappearance and synthetic rates using each subject's $n-6$ fatty acid kinetic constants and steady state masses $\left(M_{j}\right)$. For example, $R_{0,2}$ represents the amount of $18: 2 n-6$ that exits the plasma and $R_{0,1}$ is the amount of $18: 2 n-6$ passing trough the system. 
Table 3. Total plasma fatty acids.

\begin{tabular}{|c|c|c|c|c|c|c|c|c|c|c|c|c|}
\hline \multicolumn{13}{|c|}{ Plasma fatty acids $(\mu \mathrm{g})$} \\
\hline \multirow{2}{*}{$\begin{array}{l}\text { compartment/n-6 } \\
\text { fatty acid }\end{array}$} & \multicolumn{12}{|c|}{ Subject ID } \\
\hline & 82 & 83 & 84 & 86 & 87 & 88 & 89 & 90 & 91 & 92 & Mean & SD \\
\hline $\mathrm{M}_{2} / 18: 2$ & 16136 & 29212 & 19902 & 11381 & 17700 & 9768 & 20493 & 10025 & 29439 & 28913 & 19287 & 3899 \\
\hline $\mathrm{M}_{3} / 2 \mathrm{O}: 3$ & 3536 & 3424 & 2733 & 3666 & 1891 & 2057 & 3205 & 2393 & 5243 & 5369 & 3359 & 599 \\
\hline $\mathrm{M}_{4} / 2 \mathrm{O}: 4$ & 16829 & 16664 & 9122 & 14285 & 14283 & 8367 & 17419 & 10957 & 29521 & 24377 & 16182 & 3303 \\
\hline$M_{7} / 20: 2$ & 548 & 393 & 752 & nd & 747 & 1625 & 645 & 936 & 590 & 1617 & 873 & 325 \\
\hline$M_{5} / 18: 3$ & 485 & 309 & 212 & 288 & 241 & 399 & 517 & 141 & 757 & 310 & 366 & 90 \\
\hline
\end{tabular}

Plasma fatty acids determined by gas chromatography analysis. Values expressed in micrograms of total plasma volume.

Table 4. Percent of labeled fatty acids transferred through compartments.

\begin{tabular}{|c|c|c|c|c|c|c|c|c|c|c|c|c|c|}
\hline \multicolumn{14}{|c|}{ value * $100 \%$} \\
\hline \multirow[t]{2}{*}{$\%$ flux } & \multicolumn{13}{|c|}{ Subject ID } \\
\hline & 82 & 83 & 84 & 86 & 87 & 88 & 89 & 90 & 91 & 92 & Mean & SD & cv \\
\hline $\begin{array}{l}P_{2,1} \\
18: 2 n-6\end{array}$ & 0.002 & 0.001 & 0.004 & 0.002 & 0.002 & 0.002 & 0.022 & 0.014 & 0.004 & 0.001 & 0.005 & 0.002 & 0.38 \\
\hline $\begin{array}{l}P_{3,2} \\
L N A->2\end{array}$ & 0.008 & 0.003 & 0.007 & 0.029 & 0.133 & 0.011 & 0.003 & 0.010 & 0.001 & 0.177 & 0.038 & 0.033 & 0.85 \\
\hline $\begin{array}{l}P_{7,2} \\
L N A->2\end{array}$ & 0.014 & 0.004 & 0.005 & 0.009 & 0.055 & 0.007 & 0.008 & 0.002 & 0.003 & 0.018 & 0.012 & 0,008 & 0.68 \\
\hline $\begin{array}{l}P_{5,2} \\
L N A->1 E\end{array}$ & 0.019 & 0.003 & 0.010 & 0.120 & 0.072 & 0.015 & 0.009 & 0.002 & 0.007 & 0.016 & 0.027 & 0.020 & 0.74 \\
\hline $\begin{array}{l}P_{4,3} \\
20: 3 n-6\end{array}$ & $\begin{array}{l}0.943 \\
n-6\end{array}$ & 0.761 & 0.278 & 0.016 & 0.824 & 0.400 & 0.910 & 1.010 & 0.968 & 1.017 & 0.713 & 0.184 & .26 \\
\hline
\end{tabular}

Percent transfer is defined as the percentage of labeled fatty acid that remains in the system and is transferred between two compartments. Thus $P\left({ }_{3,2}\right)$ represents the percent of labeled 18:2n-6 transfered to 20:3n-6 in the scheme given in figure 1 .

Table 5. Predicted daily fatty acid intake amounts.

\begin{tabular}{|c|c|c|c|c|c|c|c|c|c|c|c|c|c|}
\hline \multirow[b]{2}{*}{$\begin{array}{l}\text { Compartment/ } \\
\text { Fatty acid }\end{array}$} & \multicolumn{13}{|c|}{$\mu \mathrm{g} \mathrm{hr} \mathbf{r}^{-1}$} \\
\hline & 82 & 83 & 84 & 86 & 87 & 88 & 89 & 90 & 91 & 92 & Mean & SD & cv \\
\hline$U_{2} / 18: 2$ & 285686 & 722857 & 139271 & 192214 & 51394 & 107307 & 200129 & 85336 & 1027571 & 151129 & 296289 & 160108 & 0.57 \\
\hline $\mathrm{U}_{3} / 20: 3$ & 6 & 11 & 54 & 98 & 12 & 16 & 34 & 32 & 33 & 68 & 36 & 15 & 0.40 \\
\hline$U_{4} / 20: 3$ & 53 & 137 & 133 & 1513 & 338 & 41 & 410 & 311 & 50 & 111 & 310 & 221 & 0.91 \\
\hline $\mathrm{U}_{5} / 20: 2$ & 6 & 1 & 16 & 145 & 52 & 102 & 19 & 159 & 3 & 65 & 57 & 30 & 0.83 \\
\hline$U_{7} / 18: 3$ & 0 & 1 & 13 & 17 & 2 & 5 & 1 & 4 & 1 & 5 & 5 & 3 & 0.57 \\
\hline
\end{tabular}

Predicted daily values were determined from each subject's feeding regimen as describted in table 1 trought the $168 \mathrm{hr}$ period. Values are expressed in micrograms per hour.

(CV 0.36) from the ${ }^{13} \mathrm{C}-\mathrm{FA}$ and $53 \mu \mathrm{g} \mathrm{h}^{-1}$ (CV 0.48 ) from the ${ }^{2} \mathrm{H}-\mathrm{FA}$.

The proportion of the plasma n- 6 FA $P_{1,}$ directed towards biosynthesis was determined and these values are given in table 4 . On average about $0.5 \%$ of the administered dose of ${ }^{13} \mathrm{C}-18: 2 \mathrm{n}-6$ and $0.3 \%$ of ${ }^{2} \mathrm{H}_{5}-20: 3 \mathrm{n}-6$ appeared in the plasma $\left(\mathrm{P}_{2,1}\right)$. The total mean percentage of plasma 18:2n-6 directed toward synthesis of all other n-6 FA was approximately $10.3 \%$ (range: $1.7-29 \%$, CV 0.62). The mean percentage of plasma ${ }^{13} \mathrm{C}-20: 3 \mathrm{n}-6$ destined for synthesis of ${ }^{13} \mathrm{C}-20: 4 n-6$ was $71 \%$ (CV 0.26 ) (table 4). This contrasts with a much smaller value $(26 \%, \mathrm{p}<.02)$ of ${ }^{2} \mathrm{H}_{5}-20: 3 \mathrm{n}-6$ destined for the synthesis of ${ }^{2} \mathrm{H}_{5}-20: 4 n-6$ (CV 0.56) (data not shown). This suggests that that the preferred substrate for 20:4n-6 biosynthesis is 20:3n-6 arising from 18:2n-6. However, when taking into consideration the percentage of each labeled substrate appearing in the plasma, and the overall percent conversion of each precursor to $20: 4 n-6$, then dietary 20:3n-6, as measured by ${ }^{2} \mathrm{H}_{5}-20: 3 n-6$ affords approximately a 6-fold greater delivery of $20: 4 n-6$ compared to $18: 2 n-6$ as measured by ${ }^{13} \mathrm{C}-18: 2 \mathrm{n}-6$. Sauerwald et al., estimated that the fractional rate of conversion (FRC) of
$18: 2 n-6$ to $20: 4 n-6$ (FRC is identical to the $P$-value used here) was between $0.4-1.1 \%$ in 3 wk-old infants and these values depended on the $\alpha$-linolenic acid content of the formula [8]. In the present study, the net mean FRC for conversion of $18: 2 n-6$ to $20: 4 n-6$ was $2.7 \%$ in these newborns.

Using the appropriate feeding regimen for each subject (table 1), intake values for $18: 2 n-6, \quad 20: 2 n-6, \quad 18: 3 n-6, \quad 20: 3 n-6$ and 20:4n-6 were calculated (table 5) that were consistent with each FA's synthetic and disappearance rates and total plasma concentration (table 2). The daily mean $( \pm S D)$ intake of 
18:2n-6 and 20:4n- 6 were calculated to be 3.0 $( \pm 1.8) \mathrm{g} \mathrm{kg}^{-1} \mathrm{~d}^{-1}$ and $2.8( \pm 2.4) \mathrm{mg} \mathrm{kg}^{-1} \mathrm{~d}^{-1}$, respectively.

The compartmental model for $18: 2 \mathrm{n}-6$ predicted an 18:2n-6 intake amount of $3.0 \mathrm{~g} \mathrm{~kg}^{-1}$ $\mathrm{d}^{-1}$ (CV 0.42) with a turnover rate through the system of $4.2 \mathrm{~g} \mathrm{~kg}^{-1} \mathrm{~d}^{-1}$ (CV 0.58) for these subjects which is consistent with the plasma concentration of $18: 2 n-6$. This is significant since results arising from this study form a basis on which to determine the effects of feeding a particular infant formulation on maintenance of plasma fatty acid homeostasis. The study also has the unique capability of isolating and comparing values of intermediate steps, such as in the conversion of $20: 3 n-6$ to $20: 4 n-6$. However, certain precautions should be considered before the current compartmental model can be successfully adapted for the determination of dietary requirements of 18:2n- 6 in infants. The high rate of turnover of $18: 2 n-6$ observed here may only be relevant to the very early postnatal period reflecting a high demand for 18:2n-6 as an energy resource. Since, during the first few days after birth intake volumes were low, then it is likely that body lipid stores supplied the remainder of the $18: 2 n-6$ as the steady state plasma concentrations did not decrease. As infants become adjusted to nursing with increased availability of energy-rich lipids (including medium chain triglycerides) this value may decrease. The values determined for the percent conversion of
$18: 2 n-6$ to $20: 4 n-6$ in the current model were of a similar magnitude to those observed in 3 wk old infants. Yet these rates of 20:4n-6 synthesis are incapable of sustaining plasma 20:4n-6 concentrations and an intake of approximately $4 \mathrm{mg} \mathrm{kg}^{-1} \mathrm{~d}^{-1}$ is needed to meet this demand, an amount that is only a fraction of that which is available from human milk.

Acknowledgements. The author acknowledges several collaborators involved in this study. Ricardo Uauy, Institute of Nutrition and Food Technology (INTA), Santiago, Chile, and Norman Salem Jr., Laboratory of Membrane Biochemistry and Biophysics, NIAAA, NIH were co-principal investigators and responsible for the study design. Adolfo Llanos and Patricia Mena were responsible for clinical exclusions, subject care and in specimen collection, Neonatology Unit, Hospital Sótero del Rio, Santiago, Chile. Yuhong Lin, Laboratory of Membrane Biochemistry and Biophysics, NIAAA, NIH had overall responsibility for quality control and preparation of isotopic labeled materials, analyses of plasma fatty acids and management of the data base.

\section{REFERENCES}

1. CARLSON SE, FORD AJ, WERKMAN SH, PEEPLES JM, COOKE RJ, TOLLEY EA. Arachidonic acid status correlates with first year growth in preterm infants. Proc Natl Acad Sci USA 1993; 90: 1073-7.
2. KOLETZKO B, AGOSTONIC, CARLSON SE, et al. Long chain polyunsaturated fatty acids (LC-PUFA) and perinatal development. Acta Paediatr 2001; 90(4): 460-4.

3. PAWLOSKY RJ, LIN YH, LLANOSA, MENAP, UAUY R, SALEM JR. N. Compartmental analyses of plasma $13 \mathrm{C}$ - and $2 \mathrm{H}$-labeled $\mathrm{n}-6$ fatty acids arising from oral administrations of $13 \mathrm{C}$ U-18:2n-6 and 2H5-20:3n-6 in newborn infants. Ped Res 2006; 60(3): 327-33.

4. LIN YH, SALEM JR. N. In vivo conversion of 18and $20-\mathrm{C}$ essential fatty acids in rats using the multiple simultaneous stable isotope method. I Lipid Res 2005; 46: 1962-73.

5. FOLCH I, LEES A, SLOANE-STANLEY GH. A simple method for the isolation and purification of total lipids from animal tissues. I Biol Chem 1957; 226: 497-509.

6. KOLETZKO B. Lipid supply and metabolism in infancy. Curr Opin Clin Nutr Metab Care 1998; 1: 171-7.

7. DEMMELMAIR H, ISER B, RAIH-PFEIFFER A, KOLETZKO B. Comparison of bolus versus fractionated oral applications of [13C]-linoleic acid in humans. Eur / Clin Invest 1999; 29: 603-9.

8. SAUERWALD TU, HACHEY DL, JENSEN CL, CHEN H, ANDERSON RE, HEIRD WC. Effect of dietary $\alpha$-linolenic acid intake on incorporation of docosahexaenoic and arachidonic acids into plasma phospholipids of term infants. Lipids 1996; 31(Suppl): 131S-135S. 